\title{
The Effectiveness of Sports Programs in Improving the Social Interaction of Children with Down Syndrome
}

\author{
Ahmed K. Hassan ${ }^{1,2, *}$, Ahmed R. Elsayed ${ }^{3}$ \\ ${ }^{1}$ Department of Physical Education, College of Education, King Faisal University, KSA \\ ${ }^{2}$ Department of Team Sports and Racket Games, Faculty College of Physical Education, Minia University, Egypt \\ ${ }^{3}$ Department of Special Education, College of Education, King Faisal University, KSA
}

Received October 23, 2021; Revised December 27, 2021; Accepted January 16, 2022

\section{Cite This Paper in the following Citation Styles}

(a): [1] Ahmed K. Hassan, Ahmed R. Elsayed, "The Effectiveness of Sports Programs in Improving the Social Interaction of Children with Down Syndrome," International Journal of Human Movement and Sports Sciences, Vol. 10, No. 1, pp. 31 - 37, 2022. DOI: 10.13189/saj.2022.100105.

(b): Ahmed K. Hassan, Ahmed R. Elsayed (2022). The Effectiveness of Sports Programs in Improving the Social Interaction of Children with Down Syndrome. International Journal of Human Movement and Sports Sciences, 10(1), 31 - 37. DOI: 10.13189/saj.2022.100105.

Copyright $\mathrm{C} 2022$ by authors, all rights reserved. Authors agree that this article remains permanently open access under the terms of the Creative Commons Attribution License 4.0 International License

\begin{abstract}
Paying attention to learners with special needs is essential to achieving the principle of equal educational opportunities for all. This study is aimed at determining the effectiveness of sports programs in improving the social interaction of children with Down syndrome. The sample consisted of 12 children with Down syndrome. Their ages ranged from 8 to 14 years, and their IQ ranged from 50 to 70 . They were from $\mathrm{Al}$ Najashi School in Al Hofuf, Al Hasa. The children were asked questions to gain preliminary data about children with Down syndrome. A scale was used to measure and assess their social interaction, and the efficacy of the sports programs in their social interaction was obtained. The results show that there are differences in the social interaction of group members in the test conducted before participation in the program (pre-test) as compared to the test conducted after participation in the program (post-test). There are also statistically significant differences among the experimental and control groups in their social interaction, in favor of the experimental group. There were no differences in the social interaction in the experimental group between the post- and follow-up tests. This shows the effectiveness of sports programs in improving social interaction in children with Down syndrome, as well as the continuing effectiveness in improving social interaction for these children during the follow-up period. The study recommends that sports programs be used to improve social interaction skills in
\end{abstract}

children with Down syndrome.

Keywords Sports Activities, Social Interaction, Down Syndrome

\section{Introduction}

Ensuring the proper care of children with disabilities is one of the most important social issues in most states today. Because of their cognitive, physical, social and academic challenges, these children are in dire need of quality care and services. Children with intellectual disabilities usually garner the most public attention out of these groups, and Down syndrome (DS) is one of the most well-known categories of intellectual disability around the world due to the physical and social characteristics that distinguish people with DS from other people with intellectual disabilities. DS is the most common chromosomal disorder, occurring in a range of between one-in-one-thousand $(1$ in 1,000) to one-in-one-thousand-one-hundred $(1$ in 1,100) live births worldwide. With improved medical and surgical care, the life span of people with DS has improved significantly over recent decades [11]. DS is defined as a disorder resulting from trisomy of human chromosome 21 , which leads to many abnormalities in the respiratory system, heart, blood vessels, sensory organs and digestive system; 
and can cause diseases of the blood, immune system, endocrine glands, skeletal muscles, kidneys and genitourinary system. Moreover, individuals may experience differences in anatomy, such as a round and flat face; epicanthic folds; low, small-set ears that may be folded; a flat nose; a short neck; a protruding tongue; short stature; small hands and fingers, with only one fold on the palms; and small feet. With regard to the developmental and cognitive aspects, these individuals may face learning difficulties, as the majority of children with DS have some form of intellectual disability, with low IQs and a weak memories being the most common [3]. In addition, children with DS have various developmental issues, such as developmental delays in gross motor skills and speech and language skills, as well as impaired sensory-motor integration. Children with DS also experience difficulties in terms of cognitive limitations, neurological disorders, obesity, psychosocial functioning and overall poor health [1]. However, there are skills that can be taught to counteract these difficulties. The most important factor that contributes to the development of these skills is early intervention in the development of functional skills and social communication in children with DS, as stated by Schworer et al. [12]. In terms of the cognitive aspects, the growth and learning processes related to the psychological, cultural and environmental factors are particularly important for children with DS because they need to integrate into society and enjoy independence. This is particularly important, as a lack of communication and language skills causes problems in social interaction [3].

\subsection{Statement of the Problem}

Recently, in the Arab world, the understanding of children with intellectual disabilities has been undergoing rapid development, in terms of both their educational and health levels, as well as the psychological and social aspects of their lives. Through this exploratory study, in which salient aspects of social interaction in the study sample of children with DS are identified, it was determined that these children have low levels of social interaction. This has been confirmed by the results of previous studies such as the one conducted by Ghanem [6], where it was determined that these children suffer from poor social interaction, which naturally results in social withdrawal, the loss of self-confidence and belittling of oneself, and social incompatibility for these children with DS.

Based on this information, the current study seeks to create a sports program to improve the level of social interaction in children with DS. Accordingly, the current study attempts to obtain the answer to the following question: "To what extent would the proposed program of sports activities improve the level of social interaction among children with intellectual disabilities, specifically DS?" Several sub-questions emerge from this question, and they can be summarized as follows:
1. Are there differences between the mean scores of the experimental group members in the pre- and post-tests on the social interaction scale?

2. Are there differences between the mean scores of the experimental group members on the social interaction scale in the post-test?

3. Are there differences between the mean scores of the experimental group members and the control group members in the pre- and post-tests on the social interaction scale?

\subsection{The Significance of the Research}

The theoretical and practical importance of this research is determined as follows:

1. Verifying the effectiveness of the proposed sports program in improving social interaction among children with DS.

2. Preparing a scale to measure and quantify social interaction in children with DS.

3. Preparing the proposed sports program to improve the level of social interaction among children with DS.

4. Proposing recommendations that benefit the children's parents, teachers, caregivers and those involved in the children's lives.

\subsection{Research Objectives}

The current study aims to investigate the effect of a sports program on improving the social interaction among children with DS.

\subsection{Definitions of the Main Concepts}

Sports program: An integrated educational sports activity that includes a group of social and movement games. This type of program benefits the individual as a whole and develops them physically, mentally, psychologically, socially and educationally.

Social interaction: The process by which individuals express themselves to others around them, and exchange dialogue, discussion and communication with others. This means there is a need for participants and there needs to be cooperation between people in common social situations. These interactions may be verbal, non-verbal or both, and are determined by the nature of the social situation in which the individual is present. Therefore, this phenomenon requires cooperation, communication and social demand.

Down syndrome (DS): A chromosomal abnormality that is one of the main causes of intellectual disability. It occurs before birth and is caused by an error in the number of chromosomes created during cell division after fertilization of the egg by the sperm. This abnormality can be determined in two ways. The first is Trisomy 21, where three chromosomes are created instead of the usual two, resulting in extra genetic material in chromosome 21 . The 
second is looking at the total number of chromosomes. Due to the extra copy from chromosome 21 , the number of chromosomes in an individual with DS is 47 , instead of 46 [2].

Children with DS: The category of children with intellectual disabilities, in the form of DS, are in primary school in integration schools in the Al-Hasa governorate.

\section{Literature Review}

Razenkova, et al. [11] indicated that DS causes great obstacles in the development of communication and social interaction skills, which are prerequisites for children's good mental health. According to many researchers, the development of communication skills at an early age in children with DS has many positive effects on the sensitivity and initiative of the child, which are traits that are traditionally used as criteria to assess the quality of communication and social interaction in this group of children. The study of Razenkova et al. [11] indicated that children with DS suffer with problems in communication behavior, which causes a problem for the mothers of these children. In light of this, Razenkova et al. designed interventions based on the communicative behavior of mothers as a factor in the development of communication skills in their children with DS. The results of the study indicated that these interventions were successful. In their study, which aimed to assess the social capabilities of children with DS, Barisnikov and Lejeune [4] found that children with DS have some problems with social knowledge, social interaction and appropriate social behavior. They also indicated that the development of positive social behaviors can contribute to improving social interaction in children with DS, which, in turn, contributes to improving their social skills.

On the other hand, Wild et al. [14] attempted to investigate the cognitive abilities and social knowledge of individuals with Smith syndrome and DS, with the study sample consisting of 21 people with Smith syndrome and 19 with DS. The results of the study showed statistically significant differences in the abilities of social thinking and social cognition between the two groups. Angélico and Prette [2] also aimed to evaluate social skills in individuals with DS by directly observing a sample consisting of 10 individuals with DS, and the results of the study showed that these individuals have deficiencies in social skills. This explains the difficulties of children with DS in many social situations, which leads to emphasizing the importance of counseling and teaching interventions to help this group develop communication and social interaction skills. Among these teaching programs, movement and sports programs can be particularly beneficial because of their ability to expose children to group activities, providing them with opportunities to interact with their peers.

A study by Ghanem [6] aimed to verify the effectiveness of a program of recreational games and stories in developing sensory awareness and reducing hyperactivity in children with DS. The study sample consisted of 20 children with DS, and the results concluded that the recreational games and stories led to a reduction in excessive activity among the sample and also led to an increase in their sensory awareness. A study by Khadi and Kumari [8] aimed to identify the effect of the personality of the child with DS, as well as the parents' and families' style of treatment towards the child, on the development of the personal and social skills of children with DS. The study sample consisted of 53 children with intellectual disabilities from three schools in Hippo and Karnataka. One of the most important findings of this study was that the level of family education affected the development of personal and social skills of the children with DS, as these circumstances gave these children the opportunity to practice various activities that contributed to the growth of their personality.

\section{Materials and Methods}

\subsection{Research Sample}

This study was conducted in the second semester of the academic year 1438-1439 AH and the first semester of the academic year 1439-1440 AH. The study sample consisted of 12 children with DS who are able to learn. We used the random sampling method to choose whose ages ranged between 8-14 years, and whose IQ scores ranged between 50-70. These children were from the intellectual education classes in Al-Hofuf, Al-Hasa governorate, and they were divided into two groups: One was experimental, while the other was the control, and both comprise six children.

\subsection{Research Instrument}

\subsubsection{Social Interaction with DS Scale}

This scale consists of twenty-seven phrases intended to describe children with DS. This scale aims to ascertain the level of social interaction in children with DS. The researchers analyzed the literature and conducted interviews with experts working in the field of intellectual disabilities. These experts included mentors, stage directors, and faculty members working in the field of education who specialize in mental health, special education and physical education research. The researchers of this study presented the preliminary scale to these professionals for their expert knowledge and, after incorporating their feedback, the final iteration of the scale to be used in the study was completed. In terms of internal consistency, the correlation coefficients ranged between the score of each of the scale statements, and the total score of the scale was between 0.66 and 0.96 . To 
calculate the reliability of the scale, the researchers used the application and re-application method on a sample of thirty children with DS from the same research community and outside the original sample, with a time interval of fifteen days between the first and second applications. The correlation coefficient between the first and second applications was 0.93 , which was a statistically significant correlation coefficient, which indicated the stability of the scale. The researchers used Cronbach's alpha by applying it to a sample of children. The alpha coefficient of the scale reached 0.94 , with a statistical coefficient at $\mathrm{P} \leq 0.01$, which indicates that the scale has an acceptable degree of reliability.

\subsubsection{Sports Program}

The program aims to:

- Detect the most prevalent deficiencies in social interaction in children with DS that need improvement; and

- Verify the effectiveness of the sports program in improving social interaction among children with DS.

The program objectives include:

- Children with DS acquiring the skills of social interaction under investigation;

- Increasing the awareness of the skills of social interaction under investigation in children with DS;

- Children with DS practicing different and varied activities that contribute to the development of the social interaction skills under discussion;

- Children with DS using the skills they acquire from the program in their work and in simple tasks that are part of their daily life;

- Children with DS expressing themselves through the activities of the program; and

- Providing children with DS with basic information about the activities.
The principles behind developing the program include:

The content of the program must be commensurate with its objective;

- The age characteristics, in terms of the mental age of the stage under consideration, must be taken into account when formulating the program content;

- The selected activities be commensurate with the age stage under consideration;

- The program must contain multiple easy activities that are not too difficult to ensure that the children with DS do not get bored;

- The games and activities must not be limited to one class period;

- The security and safety factors in the program activities must be taken into account;

- The content must be concerned with activities that test fine motor skills;

- The activities provided should allow the children with DS to work with the group;

- The materials provided for the activities must appeal to multiple children with DS;

- The activities must be interesting enough to arouse the attention of children with DS;

- The program activities should include activities to develop life skills; and

- The program must achieve its goal.

As for the content, the sports program contains an assortment of different movement activities that are essential activities for children in general and for children with DS in particular. The program provides opportunities for children to practice group sports activities that contribute to the development of their social interaction skills, as well as reducing their repetitive, stereotyped behaviors.

Table 1. The content, objectives and techniques used in the sports program

\begin{tabular}{|c|c|c|}
\hline Content of the session & Objectives of the session & Technicians \\
\hline $\begin{array}{c}\text { Acquaintance and introduction to } \\
\text { the program }\end{array}$ & $\begin{array}{c}\text { Meeting between the researchers and the members of the } \\
\text { experimental group, and an introduction to the program. }\end{array}$ & Modeling and reinforcement \\
\hline Sports activity: Jumping into hoops & Children with DS acquiring social interaction skills. & Modeling and reinforcement \\
\hline Group activity: Building with blocks & $\begin{array}{c}\text { Increasing the awareness of social interaction skills in children } \\
\text { with DS. }\end{array}$ & Modeling and reinforcement \\
\hline Sports activity: Passing the ball & $\begin{array}{c}\text { Practicing passing activities among themselves to promote } \\
\text { team play in children with DS. }\end{array}$ & Modeling and reinforcement \\
\hline Athletic activity: Running & $\begin{array}{c}\text { Practicing running activities and congratulating the winner to } \\
\text { promod sportsmanship. }\end{array}$ & Modeling and reinforcement \\
\hline Sports activity: Tug of war & $\begin{array}{c}\text { Practicing tug of war by dividing the group into two teams and } \\
\text { congratulating the winner to promote good sportsmanship. }\end{array}$ & Modeling and reinforcement \\
\hline $\begin{array}{c}\text { Sports activity: Shooting the ball } \\
\text { into the basket }\end{array}$ & $\begin{array}{c}\text { Aiming and getting the ball into the basket and congratulating } \\
\text { the winner to promote good sportsmanship. }\end{array}$ & Modeling and reinforcement \\
\hline Sports activity: Jumping & $\begin{array}{c}\text { Practicing jumping and congratulating the winner to promote } \\
\text { good sportsmanship. }\end{array}$ & Reinforcement \\
\hline $\begin{array}{c}\text { Post-test on the social interaction } \\
\text { scale }\end{array}$ & Applying the social interaction scale to the sample. & Reinforcement \\
\hline Final session & Ending the program and rewarding the children. & Reinforcement \\
\hline
\end{tabular}


Table 2. The statistical significance of the differences between the mean scores of the pre- and post-tests for the experimental group on the scale of social interaction $(\mathrm{N}=6)$.

\begin{tabular}{|c|c|c|c|c|c|c|}
\hline Subscale & Pre/post-test & Mean & Mean of ranks & $\begin{array}{c}\text { Sum of } \\
\text { ranks }\end{array}$ & Z-score & $\begin{array}{c}\text { Improvement } \\
\text { rate }\end{array}$ \\
\hline \multirow{2}{*}{ Social interaction } & Pre & 50.83 & 0.00 & 0.00 & \multirow{2}{*}{$2.24 *$} & \multirow{2}{*}{$37.38 \%$} \\
\cline { 2 - 6 } & Post & 69.83 & 3.49 & 22.00 & & \\
\hline
\end{tabular}

$* \mathrm{p}<.05 . * \mathrm{p}<.01$.

Table 3. The statistical significance of the differences between the mean of the post- and follow-up tests for the experimental group on the scale of social interaction $(\mathrm{N}=6)$

\begin{tabular}{|c|c|c|c|c|c|c|c|}
\hline Subscale & \multicolumn{3}{|c|}{ Post-test } & \multicolumn{4}{c|}{ Follow-up test } \\
\hline \multirow{2}{*}{$\begin{array}{c}\text { Social } \\
\text { interaction }\end{array}$} & Mean & Mean of ranks & $\begin{array}{c}\text { Sum of } \\
\text { ranks }\end{array}$ & Mean & Mean of ranks & $\begin{array}{c}\text { Sum of } \\
\text { ranks }\end{array}$ & Z-score \\
\cline { 2 - 9 } & 69.83 & 3.00 & 12.00 & 69.33 & 3.00 & 3.00 & $1.34 *$ \\
\hline
\end{tabular}

Table 4. The statistical significance of the differences between the mean scores of the pre- and post-tests for the experimental and control groups on the social interaction $(\mathrm{N}=6)$

\begin{tabular}{|c|c|c|c|c|c|c|c|}
\hline \multirow{2}{*}{ Subscale } & \multicolumn{3}{|c|}{ Control group=6 } & \multicolumn{3}{c|}{ Experimental group = 6 } \\
\hline \multirow{2}{*}{ Social interaction } & Mean & $\begin{array}{c}\text { Mean of } \\
\text { ranks }\end{array}$ & Sum of ranks & Mean & $\begin{array}{c}\text { Mean of } \\
\text { ranks }\end{array}$ & $\begin{array}{c}\text { Sum of } \\
\text { ranks }\end{array}$ & Z-score \\
\cline { 2 - 9 } & 69.83 & 3.49 & 21.45 & 69.83 & 9.48 & 65.10 & $2.91^{*}$ \\
\hline
\end{tabular}

\section{Results}

Data analysis was conducted to determine the differences in social interaction before and after the sports program, and determine the differences in social interaction between the post-test and the follow-up test. This information is presented in the tables above.

In Table 2, there are statistically significant differences in the experimental group, at the level of 0.05 , between the mean ranks of the scores of the pre- and post-tests on the scale of social interaction, in favor of the post-test. The improvement rate reached $37.38 \%$, which indicates the effectiveness of the proposed program in improving social interaction in children with DS.

In Table 4, there are no statistically significant differences between the mean ranks of the scores of the post-test and follow-up test on the scale of social interaction among children of the experimental group.

Table 3 shows that there are statistically significant differences, at the level of 0.05 , between the mean ranks of the scores of the experimental group members and the mean ranks of the scores of the control group members on the social interaction scale in the post-test. The biggest benefit was seen to be in the experimental group, which indicates the effectiveness of the proposed program in improving the level of social interaction among the children of the experimental group.

\section{Discussion}

It is evident from the results in Table 2 that there are statistically significant differences in the mean scores of the members of the experimental group on the measurement of social interaction in the post-test when compared to the pre-test, and it is in favor of the post-test. The researchers attributed this to the positive effect of the program, which effectively and positively contributed to improving social interaction, as the sports program contained movement and social games that were designed in a manner that combined competition with performance, joy and pleasure. The movement games, carried out in the form of competitions, played a major role in increasing the effectiveness of the communication in children with DS, which led to improving their social interaction.

This is in agreement with the study of Lagrca and Santagrossi [9], which found that it is possible to improve the social interaction of children through programs that use diverse and interesting methods in their teaching, and that teaching children with intellectual disabilities to improve their social skills can be accomplished by using this style of play. This also agrees with Demmers [5] view that teaching children with intellectual disabilities about social behavior leads to modification of their behavior and their acquiring and improving social skills.

The researchers believe that playing leads to significant changes in the behavior of children with DS and contributes to removing them from the state of aversion and distance in which the usually operate, thereby improving social interaction between them and others. This is consistent with what Ivory and Mccolum [7] stated, in that movement and games programs lead to fundamental modifications in behavior, where children interact with each other by establishing dialogue, communication and support as a team, leading to 
improved social interaction.

The researchers of this study also determined that the movement and social games contained in the program brought together competition and encouragement, which exposed the children to situations that encouraged them to use their initiative while increasing their self-confidence. Urging them to practice and perform contributed to their excitement for playing and being active, as there were equal opportunities for both dynamic play situations and social play situations, which led to the improvement of their social interaction.

The results of Table 3 also indicate that there are statistically significant differences between the members of the experimental and control groups in social interaction, in favor of the post-test of the experimental group. The researchers attributed this improvement to the interest of the experimental group members in practicing movement and social activities and games, which all contributed to the increase in their social interaction, their participation in playing and talking, and the lack of contact with the members of the control group. Additionally, the control group's perspectives, experiences and education were lacking, as compared to the members of the experimental group who received these aspects due to their enrollment in the sports program and their integration with their peers. The researchers believe that forming friendships is an important element of social growth, along with interaction between them and others, as this is where the child with DS learns the principles of giving and learns about their roles and duties in their friendships, thus helping them gain the necessary experiences in order to assume responsibility.

Demmers' [5] research confirmed that teaching social skills helps with modifying some behavioral styles and patterns of children with DS who suffer from some behavioral disorders, and it also helps in improving their performance. In this regard, Visser [13] mentions that the diversification of activities and games offered to children plays a great role in their levels of preoccupation and interaction with others, allowing the lessons to be absorbed with more ease, thus availing these skills to be used in other activities, as the tasks stimulate a sense of self-worth in the children. Thus, the researchers of this study acknowledge that movement and social games contributed greatly to the better results of the members of the experimental group over the control, which was reflected in their improved social interaction, as playing leads to a change in the way that they interact with the social environment, thus achieving the second goal of the study.

It was also evident from the results of Table 4 that there were no statistically significant differences between the mean scores of the experimental group in the post- and follow-up tests that measured social interaction. The researchers attributed this to the last phase of the program, in which the children were re-taught some social skills and abilities, as well as the movement games that helped with social interactions. By reteaching these skills, there is an absence of relapse after the end of the program as the impact and effectiveness of the program is being prolonged. Play contributes greatly to developing social interaction skills and emotional maturity in children, as the child moves out of the self-centered frame of mind and instead learns to exchange roles and accept defeat in the same spirit as when accepting victory, thereby verifying the third assumption.

\section{Conclusions}

The sports program used in this study has a significant positive effect on social interaction skills of children with DS. This is based on the presence of statistically significant differences in social interaction in children with DS between the pre- and post-tests for the experimental group under investigation. The percentage improvement of the experimental group in their social interaction reached $37.38 \%$, which indicates an improvement in the experimental group as a result of their exposure to the activities in the sports program.

\section{Recommendations}

In light of these research results, the researchers recommend the following:

1. Offer the use of the sports program to those in charge of educational programs and institutions in the field of special needs education in order to improve the basic communication skills of children with DS.

2. Educate families with a child with DS about the importance of these programs and their impact on the children so that these families can consider educational institutions which offer them.

3. Provide all the necessary devices and tools in order to implement the codified programs and to ensure their safety and continuous maintenance.

4. Teach those tasked with developing the skills of children with DS how to develop the children's social interaction skills by holding courses to on how sharpen these skills.

5. Use modern scientific methods in setting up teaching programs for children with DS, in proportion to their abilities and aptitudes.

\section{Acknowledgements}

The authors acknowledge the Deanship of Scientific Research at King Faisal University for the financial support for the research, authorship and publication of this research in Track Annual Research, Number (160146). 


\section{REFERENCES}

[1] Abd El-Hady, S., Abd El-Azim, F. \& El-Talawy, H. (2018). Correlation between cognitive function, gross motor skills and health - Related quality of life in children with Down syndrome, The Egyptian Journal of Medical Human Genetics. (19), 97-101. http://dx.doi.org/10.1016/j. ejmhg.2017.07.006

[2] Angélico, A. \& Prette, A. (2011). Assessment of the social skills repertory of adolescents with Down's Syndrome, Psicologia: Reflexão e Crítica. 24(2), 207-217.

[3] Barbosa, et al. (2018). Augmentative and alternative communication in children with Down's syndrome: a systematic review, BMC Pediatrics. 18(160), 1-16. https://doi.org/10.1186/s12887-018-1144-5

[4] Barisnikov, K. \& Lejeune, F. (2018). Social knowledge and social reasoning abilities in a neurotypical population and in children with Down syndrome. PLoS ONE 13(7). https://doi.org/10.1371/journal.pone.0200932

[5] Demmers, L. A. 2000. Effective Mainstreaming for the Learning Children With Down Syndrome, with Behavior Problems. Psychological Abstracts,66(1), 146-180.

[6] Ghanem, Enas Mohamed Mohamed. 2011. Motive story and recreational games by using 3purpose tools for the development of sensory-motive awareness and reduction of the more activity for the mentally handicapped. World journal of sport sciences, 4 (2), 126-13

[7] Ivoryj and Mccolum, J. 1999: Effects of social and isolate

toys on social play in an inclusive setting Journal of special education, 4(32).

[8] Khadi, V. and Kumari, P. B. 2010. Influence of child's, parental and familial characteristics on social and personal skills of mentally challenged children, Karnataka J. Agric. Sci., 23 (5), 778-782.

[9] Lagreca, A.M. and Santagrossi, D.A.1998. Social Skills Training with Elementary School Students: A behavioral group approach Journal of Consulting and clinical psychology.

[10] Lee, A., Knafl, K. \& Riper, M. (2021). Family variables and quality of life in children with Down Syndrome: A Scoping Review. International Journal of Environmental Research and Public Health, 18(419), https://doi.org/10.33 90/ ijerph18020419

[11] Razenkova, Y., Odinokova, G., Ayvazyan, E. (2018). Maternal communicative behavior as a factor in the development of communication in children with Down Syndrome. Psychology in Russia: State of the Art, 11(3), 111-127. doi: 10.11621/pir.2018.0308

[12] Schworer, E. K., Fidler, D. J. \& Daunhauer, L. A. (2021). Early regulatory skills and social communication development in infants with Down Syndrome, Brain Sci. 11(208), 1-13. https://doi.org/10.3390/brainsci11020208

[13] Visser, J. 2000. Managing Behavior in Classroom .London: David Fulton Publishers.

[14] Wilde, L., Mitchell, A. \& Oliver. C. (2016). Differences in social motivation in children with Smith-Magenis Syndrome and Down Syndrome, J Autism Dev Disord. (46), 2148-2159. DOI 10.1007/s10803-016-2743- 